\title{
Influência do teor de umidade, da porosidade e do intervalo de tempo até a aplicação da mistura solo-cimento em pavimento rodoviário
}

\author{
Max Alberto Cancian¹, Victor Antonio Cancian², Heliana Barbosa Fontenele ${ }^{3}$ e Carlos José Marques da Costa \\ Branco ${ }^{4}$ e Raquel Souza Teixeira ${ }^{5}$
}

\begin{abstract}
Resumo: Pretende neste trabalho avaliar a influência do teor de umidade, da porosidade e do intervalo de tempo até a aplicação, sobre a resistência à compressão simples (RCS) de misturas de solo-cimento. Foram realizadas três baterias de ensaios, usando misturas de solo-cimento compactadas, com 6 e $7 \%$ de cimento. Na primeira bateria foi utilizada a umidade ótima ( $\omega_{\text {ótima }}$ ) e energia Normal de Proctor, na segunda usou-se $\omega_{\text {ótima }}+1 \%$ e energia Normal de Proctor e na terceira foi utilizada a $\omega_{\text {ótima }}+1 \%$ e energia de compactação alterada, a fim de verificar a influência do teor de umidade. Para cada dosagem as compactações ocorreram em 10 intervalos de tempo até a aplicação, variando de 0 min a $6 \mathrm{~h}$, com o intuito de verificar, no desempenho mecânico, a influência do intervalo de tempo até a aplicação do solo-cimento. Os resultados apontaram que o aumento no intervalo de tempo até a aplicação diminui a RCS e este tempo é limitado para atingir a RCS mínima requerida de $21 \mathrm{~kg} / \mathrm{cm}^{2}$, variando conforme o teor de cimento, teor de umidade e energia de compactação. Quando a compactação se deu com $\omega_{\text {ótima }}+1 \%$ foram obtidos maiores valores de RCS, para os mesmos tempos de aplicação. Em todas as dosagens verificou-se que quanto mais baixa a porosidade da mistura solo-cimento melhor foi o desempenho mecânico.

Palavras-chave: resistência à compressão simples, desempenho mecânico, solo-cimento.
\end{abstract} Abstract: In this paper it intends to evaluate the moisture content, porosity and time lapse until the application influences
over their unconfined strength of soil-cement mixtures. They were made three groups of laboratorial tests, over compacted
soil-cement mixtures, using 6 and $7 \%$ Portland cement. In the first group, the dosage mixture was made under the optimum
humidity $\left(\omega_{\text {optimun }}\right)$ and Proctor normal energy. In the second group, the dosage mixture was made under the $\omega_{\text {optimun }}+1 \%$
and Proctor normal energy. In the third group, the dosage mixture was made under the $\omega_{\text {optimun }}+1 \%$ and altered Proctor
energy. These conditions were adopted for moisture content influence verifications. Over each dosage mixture, the compac-
tion was made after 10 time lapses between the until application works, varying for 0 min to $6 \mathrm{~h}$, to verify in the mechanical
performance, the influence of the time lapse until the application influences. The results appointed to the unconfined strength
decreasing for the increasing time lapse until the mixture application and this time lapse was limited for the $21 \mathrm{~kg} / \mathrm{cm}^{2}$
minimum unconfined strength required, varying according to the cement content, moisture content and compaction energy.
When the compaction was made with the $\omega_{\text {optimun }}+1 \%$, the unconfined strength obtained was higher, for the same time lapse
until application. For all dosage mixtures was verified that the better mechanical performance occurred to the lower mixture
porosity.

Keywords: compressive strength, mechanical performance, soil-cement.

\section{INTRODUÇÃO}

Segundo a Associação Brasileira de Cimento Portland (ABCP, 2013), até o ano de 2013, o país tinha mais de 25 mil quilômetros de rodovias executadas com bases ou sub-bases com solo- cimento. A primeira rodovia federal a usar esta solução de engenharia foi a Caxambú-Areia no estado de Minas Gerais.

Solo-cimento é o material proveniente da mistura de solo, cimento Portland e água, em proporções previamente

\footnotetext{
${ }^{1}$ Max Alberto Cancian, Coordenador de Engenharia, DNIT/PR.

(max.cancian@dnit.gov.br)

2 Victor Antonio Cancian, Mestrando em Engenharia de Edificações e

Saneamento, UEL. (victorcancian@hotmail.com)

${ }^{3}$ Heliana Barbosa Fontenele, Departamento de Construção Civil, UEL.

(heliana@uel.br)

${ }^{4}$ Carlos José Marques da Costa Branco, Departamento de Construção

Civil, UEL. (costabranco@uel.br)

${ }^{5}$ Raquel Souza Teixeira, Departamento de Construção Civil, UEL.

(raquel@uel.br)
}

Manuscrito recebido em 11/04/2016 e aprovado para publicação em 19/09/2016.

Este artigo é parte de TRANSPORTES v. 25, n. 1, 2017. ISSN: 2237-1346 (online). DOI:10.14295/transportes.v25i1.1126 determinadas por processo próprio de dosagem em laboratório, de forma a apresentar determinadas características de resistência e durabilidade quando utilizado como base de pavimento rodoviário. A mistura deve apresentar uma resistência mínima à compressão simples aos sete dias de cura de $21 \mathrm{~kg} / \mathrm{cm}^{2}$ (DNIT-ES143/2010).

Em rodovias, para a mistura solo-cimento, pode ser usado o solo do próprio leito da via a ser implantada, podendo ser misturado "in loco" com equipamentos específicos ou utilizar solos de jazidas próximas ao local da obra, que podem ser homogeneizados em uma central.

O material solo constitui a maior parte da mistura, enquanto a quantidade de cimento Portland adicionada varia entre 5 e $10 \%$ em massa e a água é acrescentada conforme as propriedades do solo e do cimento para conferir à mistura as propriedades necessárias de resistência mecânica (LOPES, 2002).

Os solos com teor de areia superior a $50 \%$ são os mais apropriados para misturas com cimento, por proporcionarem maior durabilidade com porcentagens menores de cimento. Os solos com alta carga orgânica não podem ser utilizados (LOPES, 2002). 
O solo mais indicado para um pavimento como base de solo-cimento é o do local da obra, se este atender os critérios técnicos, diminuindo os custos com transporte.

O solo-cimento apresenta-se como um material cimentado. Neville (1997) menciona que o ao retardar o lançamento do cimentado ou aumentar o intervalo de tempo até a aplicação deste, caso este tempo seja superior ao tempo de pega do cimento utilizado na mistura, acarretará na ruptura dos silicatos, promovendo o decréscimo de resistência do material cimentado.

Ao se empregarem as técnicas de estabilização química com cimento em solos, o tempo entre mistura e compactação é um aspecto de significativa importância para a boa qualidade mecânica das misturas. Se na mistura, já ocorreram reações de cimentação de curto prazo antes da compactação, certamente parte do estabilizante adicionado ao solo foi utilizada na efetivação dessas reações (FREIRE, 2008).

A reação química entre o cimento e a água inicia-se durante a operação de mistura, estando os elementos resistentes provenientes da hidratação formados ao fim de aproximadamente uma hora. Um aumento do tempo de mistura e o atraso da compactação conduzem a diminuição quantidade de água, a consequentemente o decréscimo da massa especifica seca, acarretando na diminuição da durabilidade e da resistência da mistura solo-cimento compactada (VITALI, 2008).

Desde o começo da utilização de solo estabilizado com cimento em pavimentos rodoviários, seja em base ou sub-base foi observado, em campo, o surgimento de trincas e deflexões excessivas.

Nota-se nos projetos de pavimento com uso de solo estabilizado com cimento para base ou sub-base rodoviária que, em muitos casos, não são realizados ensaios laboratoriais para avaliar o desempenho da mistura.

Alguns projetistas justificam a não realização de uma avaliação mais criteriosa das misturas, ao tempo e ou gastos necessários para execução desta avaliação. Por isso, frequentemente, são observadas inconsistências em projetos de solo-cimento que geram sérios problemas no pavimento de rodovias brasileiras. Além disso, projetistas, executores e fiscalizadores não demonstram a devida importância à realização dos ensaios com a mistura solo-cimento compactada em campo.

A dosagem final da mistura deve considerar três variáveis principais: a massa específica aparente seca, a quantidade de água e teor de cimento, que influenciam diretamente na resistência mecânica do solo-cimento, e, além disso, deve ser considerado o intervalo de tempo até a aplicação (tempo entre a homogeneização e compactação). Oliveira (2011) afirma que a qualidade do solo-cimento está intimamente relacionada a fatores como: a qualidade e quantidade da água, o tipo e grau de compactação, tempo de cura, a eficiência da mistura, intervalo de tempo até a aplicação e tipo de solo.

Sendo assim, as definições da dosagem da mistura e do intervalo de tempo até a aplicação resultam em estruturas mais econômicas, com o uso de mão-de-obra e equipamentos disponíveis, e que fiquem em harmonia com as diferentes condições de contorno das obras.

Estudos recentes realizados no Brasil sobre a sensibilidade dos constituintes da mistura de solo-cimento, como teor de umidade, porosidade e quantidade de cimento, demonstram resultados diferentes devido à tipologia de cada solo estudado. Entretanto, a maioria deles evidencia esses componentes como os mais importantes em uma mistura de solo-cimento, mas não levam em consideração a influência do intervalo de tempo até a aplicação no comportamento mecânico.

Nos trabalhos apresentados por Parente (2002), Consoli et. al (2007) e Vitali (2008) não foi avaliada para as misturas solo-cimento a influência do intervalo de tempo até a aplicação na resistência final do material e na determinação do tempo máximo que cada mistura (variando no teor de cimento e umidade) pode ser aplicada.

Felt (1955) e West (1959), em trabalhos realizados nos Estados Unidos, avaliaram a influência do intervalo de tempo até a aplicação da mistura solo-cimento sobre a resistência à compressão simples. Os autores evidenciaram a queda da resistência do solo-cimento com o aumento do intervalo de tempo até a aplicação.

O DNIT, em sua especificação de serviço 143/2010 limita o tempo entre a mistura e a compactação final do solo-cimento. Para mistura em central (usina) o início da compactação é limitado em 1 hora após o término da homogeneização. Já para misturas realizadas na pista essa especificação limita o tempo máximo, entre o início e o fim, para adição de água em 3 horas.

A adoção das quantidades de cimento e água inadequados para a mistura solo-cimento, assim como a execução errada da mesma, acarretam na rápida deterioração da camada de pavimento. Por isso, possivelmente deverá ser realizada manutenção ou outra camada de pavimento, gerando custos financeiros adicionais para a rodovia.

Tecnicamente, a falta de informações sobre os materiais, as modificações causadas pela estabilização do solo com cimento Portland e o intervalo de tempo máximo para a aplicação dessa mistura, pode levar a divergências entre o desempenho estabelecido em projeto e o real obtido em campo.

O problema então se mostra explícito em relação ao comportamento da mistura solo-cimento que está diretamente relacionado aos componentes e quantidades na mistura e com o tempo para a sua aplicação. O desconhecimento das alterações realizadas por cada componente da mistura solo-cimento acarreta problemas de durabilidade, gerando gastos adicionais nas obras e segurança nas rodovias.

Este trabalho avalia a influência do teor de umidade, da porosidade e do intervalo de tempo até a aplicação, sobre a resistência à compressão simples de misturas de solo-cimento, visando o emprego em pavimento rodoviário.

\section{MATERIAS E MÉTODOS}

\subsection{Materiais}

A jazida do solo usado neste trabalho está localizada no km 127 da Rodovia Federal BR-487/PR, no município de Tuneiras do Oeste- PR de responsabilidade do DNIT (Departamento Nacional de Infraestrutura de Transportes). As amostras tanto deformadas como indeformadas, utilizadas para o ensaio de caracterização física do solo e ensaios de compactação da mistura solo-cimento, foram retiradas a 1 metro de profundidade. 
O cimento utilizado foi o Portland do tipo II, com adições especial de composto com pozolana e resistência de $32 \mathrm{MPa}$ aos 28 dias - CP II Z-32 e a água utilizada nos experimentos foi potável. No laboratório as amostras deformadas foram secas ao ar, em seguida destorroadas, armazenadas e determinado o teor de umidade (DNER-ME 213/1994).

\subsection{Caracterização do solo de estudo}

A amostra de solo indeformada e as deformadas foram submetidas aos ensaios: Determinação da massa específica aparente de amostras indeformadas, com emprego da balança hidrostática (NBR10838/1988), massa específica dos sólidos (NBR 6508/1984), análise granulométrica por peneiramento (DNER-ME 80/1994) e sedimentação (NBR 7181/1988), limite de plasticidade (DNER-ME 82/1994) e liquidez (DNER-ME 122/1994), compactação (NBR 7182/1986) e Índice de Suporte Califórnia (DNER-ME 49/1994). Todos os ensaios foram realizados em duplicata. Foram feitas também as classificações do solo pela AASHTO (American Association of State Highway and Transportation Officials) e MCT (Miniatura, Compactado, Tropical) de acordo com a DNER-ME 256/1994 e DNERME 258/1994 (Manual de Pavimentação do DNIT-2006).

\subsection{Curva de compactação da mistura solo-cimento}

Para obter a massa específica aparente seca máxima $\left(\rho_{\text {dmax }}\right)$ e o teor de umidade ótima ( $\omega_{\text {ótima }}$ ) foram realizados dois ensaios de compactação para cada uma das misturas solo-cimento, com teores de 6 e $7 \%$ de cimento em relação à massa de solo seca (DNER-ME 216/1994). Conhecendose a umidade e a massa de solo, foi calculada a quantidade de cimento a ser adicionado na mistura e realizada a homogeneização. Para a compactação foi usado o cilindro de Proctor com dimensões de $12,7 \mathrm{~cm}$ de altura e $10,0 \mathrm{~cm}$ de diâmetro, totalizando um volume aproximado de $1000 \mathrm{~cm}^{3}$, soquete pequeno de $2.500 \mathrm{~g}, 25$ golpes por camada e 3 camadas, utilizando a energia Normal de Proctor (NBR 7182/1986).
Realizada a compactação, com os valores de massa específica aparente seca e teor de umidade, dos cinco corpos de prova compactados, foram obtidas duas curvas de compactação para cada mistura de solo-cimento, com 6 e $7 \%$ de cimento.

\subsection{Compactação dos corpos de prova de solo- cimento para os ensaios de resistência à compressão simples}

Depois de decididas as baterias de ensaios e suas respectivas dosagens, e determinados os valores de $\rho_{\text {dmax }} \mathrm{e}$ $\omega_{\text {ótima }}$ para cada teor de cimento utilizado, foi dado início a compactação.

A Tabela 1 apresenta as baterias e as características como umidade, energia de compactação, tempo para aplicação e quantidade dos ensaios realizados.

Para cada uma das baterias foi utilizado $25 \mathrm{~kg}$ de solo, para os quais foram quantificadas as massas de água e cimento, a partir do teor de umidade em que se encontravam. Foi realizada a homogeneização da mistura com o auxílio de uma betoneira e após os tempos definidos, entre a homogeneização e aplicação, foram compactados os corpos de prova para cada bateria (DNER-ME 202/1994). Foi usado para a compactação um cilindro com dimensões de $12,7 \mathrm{~cm}$ de altura e $10,0 \mathrm{~cm}$ de diâmetro, soquete pequeno de 2.500 g, 25 golpes por camada e 3 camadas iguais e consecutivas.

Nas baterias dos ensaios de 1 a 6 e de 9 a 14 foram aplicados 25 golpes, ou seja, a energia Normal. Já nas baterias $7,8,15$ e 16 foi aplicado um número maior de golpes (entre 25 e 52) até alcançar a massa específica aparente seca máxima determinada na curva de compactação. Nas baterias 1,2,9 e 10 o teor de umidade usado para a compactação foi a umidade ótima, para as demais baterias foi acrescentada água para atingir $1 \%$ acima da umidade ótima. Ao final da compactação foi conferido o teor de umidade dos corpos de prova por meio da determinação do teor de umidade (DNER-ME 213/1994).

O controle de compactação dos corpos de prova foi para o grau de compactação (GC) maior ou igual a $100 \%$

Tabela 1. Baterias e características dos ensaios

\begin{tabular}{|c|c|c|c|c|c|}
\hline Bateria & $\begin{array}{l}\text { Teor de cimento } \\
(\%)\end{array}$ & $\begin{array}{c}\text { Umidade } \\
(\%)\end{array}$ & $\begin{array}{c}\text { Energia de } \\
\text { compactação }\end{array}$ & $\begin{array}{l}\text { Intervalo de tempo até a aplicação/compactação } \\
\text { (min) }\end{array}$ & $\begin{array}{l}\text { Quantidade } \\
\text { de ensaios }\end{array}$ \\
\hline 1 & 6 & Ótima & Normal & $0 ; 15 ; 30 ; 45 ; 60 ; 90 ; 120 ; 150 ; 180$ e 360 & 10 \\
\hline 2 & 6 & Ótima & Normal & $0 ; 15 ; 30 ; 45 ; 60 ; 90 ; 120 ; 150 ; 180$ e 360 & 10 \\
\hline 3 & 6 & Ótima+1 & Normal & $0 ; 15 ; 30 ; 45 ; 60 ; 90 ; 120 ; 150 ; 180$ e 360 & 10 \\
\hline 4 & 6 & Ótima+1 & Normal & $0 ; 15 ; 30 ; 45 ; 60 ; 90 ; 120 ; 150 ; 180$ e 360 & 10 \\
\hline 5 & 6 & Ótima+1 & Normal & $0 ; 15 ; 30 ; 45 ; 60 ; 90 ; 120 ; 150 ; 180$ e 360 & 10 \\
\hline 6 & 6 & Ótima+1 & Normal & $0 ; 15 ; 30 ; 45 ; 60 ; 90 ; 120 ; 150 ; 180$ e 360 & 10 \\
\hline 7 & 6 & Ótima+1 & Alterada & $0 ; 15 ; 30 ; 45 ; 60 ; 90 ; 120 ; 150 ; 180$ e 360 & 10 \\
\hline 8 & 6 & Ótima+1 & Alterada & $0 ; 15 ; 30 ; 45 ; 60 ; 90 ; 120 ; 150 ; 180$ e 360 & 10 \\
\hline 9 & 7 & Ótima & Normal & $0 ; 15 ; 30 ; 45 ; 60 ; 90 ; 120 ; 150 ; 180$ e 360 & 10 \\
\hline 10 & 7 & Ótima & Normal & $0 ; 15 ; 30 ; 45 ; 60 ; 90 ; 120 ; 150 ; 180$ e 360 & 10 \\
\hline 11 & 7 & Ótima+1 & Normal & $0 ; 15 ; 30 ; 45 ; 60 ; 90 ; 120 ; 150 ; 180$ e 360 & 10 \\
\hline 12 & 7 & Ótima+1 & Normal & $0 ; 15 ; 30 ; 45 ; 60 ; 90 ; 120 ; 150 ; 180$ e 360 & 10 \\
\hline 13 & 7 & Ótima+1 & Normal & $0 ; 15 ; 30 ; 45 ; 60 ; 90 ; 120 ; 150 ; 180$ e 360 & 10 \\
\hline 14 & 7 & Ótima+1 & Normal & $0 ; 15 ; 30 ; 45 ; 60 ; 90 ; 120 ; 150 ; 180$ e 360 & 10 \\
\hline 15 & 7 & Ótima+1 & Alterada & $0 ; 15 ; 30 ; 45 ; 60 ; 90 ; 120 ; 150 ; 180$ e 360 & 10 \\
\hline \multirow[t]{2}{*}{16} & 7 & Ótima+1 & Alterada & $0 ; 15 ; 30 ; 45 ; 60 ; 90 ; 120 ; 150 ; 180$ e 360 & 10 \\
\hline & & & & Total & 160 \\
\hline
\end{tabular}

1.Energia alterada: aplicação de número de golpes até obter-se a massa específica aparente seca máxima determinada na curva de compactação. 
(DNIT-ES 143/2010) e o desvio no teor de umidade $(\Delta \omega)$ de $\pm 1 \%$ em relação ao especificado nas dosagens.

Em seguida o corpo de prova tinha sua massa mensurada e com o seu volume, obtinha-se a massa específica aparente da mistura compactada. Com o teor de umidade medido foi obtida da massa específica aparente seca da mistura após sua compactação. Os corpos de prova foram levados para a câmara úmida, à temperatura de $23 \pm 2{ }^{\circ} \mathrm{C}$ e umidade relativa do ar não inferior a $95 \%$, onde permaneceram por 7 dias para a cura (DNER-ME 202/1994).

\subsection{Ensaios de resistência à compressão simples dos corpos de prova de solo-cimento}

Depois de curados os corpos de prova tiveram suas massas aferidas e foram levados para a imersão com água em um tanque, onde permaneceram por 4 horas. Logo após o período de imersão cada corpo de prova foi retirado do tanque e procedeu-se: leve enxugamento de faces externas do corpo de prova com auxílio de pano seco e limpo e medição da massa do corpo de prova com precisão de $1 \mathrm{~g}$ (DNER-ME 201/1994).

Conhecida a massa do corpo de prova antes e depois, da imersão em água por 4 horas, foi possível calcular o percentual de absorção de água. O rompimento dos corpos de prova foi realizado com auxílio de uma prensa de compressão simples com aplicação de carregamento constante na velocidade de $1,27 \mathrm{~mm} / \mathrm{min}$.

\section{RESULTADOS E DISCUSSÕES}

Na Tabela 2 estão mostrados os resultados de caracterização física do solo.

Tabela 2. Resultados dos ensaios de caracterização física do solo

\begin{tabular}{|c|c|c|c|}
\hline \multicolumn{2}{|c|}{ Ensaio } & Valor & DNIT-ES 43/2010 \\
\hline \multicolumn{2}{|c|}{ Massa específica aparente $\left(\mathrm{g} / \mathrm{cm}^{3}\right)$} & 1,41 & - \\
\hline \multicolumn{2}{|c|}{$\begin{array}{l}\text { Massa específica aparente seca } \\
\left(\mathrm{g} / \mathrm{cm}^{3}\right)\end{array}$} & 1,21 & - \\
\hline \multicolumn{2}{|c|}{ Massa específica dos sólidos $\left(\mathrm{g} / \mathrm{cm}^{3}\right)$} & 2,89 & - \\
\hline \multicolumn{2}{|c|}{ Umidade média natural (\%) } & 16,3 & - \\
\hline \multicolumn{2}{|c|}{ Limite de liquidez (\%) } & 20,2 & Máximo $40 \%$ \\
\hline \multicolumn{2}{|c|}{ Limite de plasticidade $(\%)$} & 13,2 & Máximo $18 \%$ \\
\hline \multicolumn{2}{|c|}{ Índice de plasticidade (\%) } & 7,0 & $100 \% \pm 7 \%$ \\
\hline \multicolumn{2}{|c|}{$\%$ passante \#2 1/2" } & 100 & $50-100 \% \pm 5 \%$ \\
\hline \multicolumn{2}{|l|}{$\%$ passando $\# 4,8 \mathrm{~mm}$} & 100 & Não contempla \\
\hline \multicolumn{2}{|c|}{$\%$ passando \#2,0mm } & 100 & $15-100 \% \pm 2 \%$ \\
\hline \multicolumn{2}{|c|}{$\%$ passando $\# 0,42 \mathrm{~mm}$} & 97,2 & $5-35 \% \pm 2 \%$ \\
\hline \multicolumn{2}{|c|}{$\%$ passando $\# 0,075 \mathrm{~mm}$} & 27,8 & Não contempla \\
\hline \multicolumn{2}{|c|}{$\%$ silte } & 4,7 & Não contempla \\
\hline \multicolumn{2}{|c|}{$\%$ argila } & 22,3 & - \\
\hline \multicolumn{2}{|c|}{ Classificação AASHTO } & A-2-4 & - \\
\hline \multicolumn{2}{|c|}{ Classificação MCT } & LA $^{\prime}$ & - \\
\hline \multicolumn{2}{|c|}{$\begin{array}{l}\text { Massa específica aparente seca } \\
\text { máxima }\left(\mathrm{g} / \mathrm{cm}^{3}\right)\end{array}$} & 2,00 & - \\
\hline \multicolumn{2}{|c|}{ Umidade ótima (\%) } & 11,2 & - \\
\hline \multirow{2}{*}{$\begin{array}{l}\text { Índice de Suporte } \\
\text { Califórnia }\end{array}$} & I.S.C (\%) & 14,0 & - \\
\hline & Expansão (\%) & 0,20 & - \\
\hline
\end{tabular}

Conforme a Tabela 2, o solo é classificado como uma areia argilosa. De acordo com os requisitos prescritos na DNIT-ES 143/2010 quanto aos limites de consistência e granulometria, verificou-se que ele pode ser usado em mis- turas de solo-cimento. Na Figura 1 são apresentadas as curvas de compactação do solo-cimento, com teores de 6 e $7 \%$ de cimento em relação à massa de solo seca.

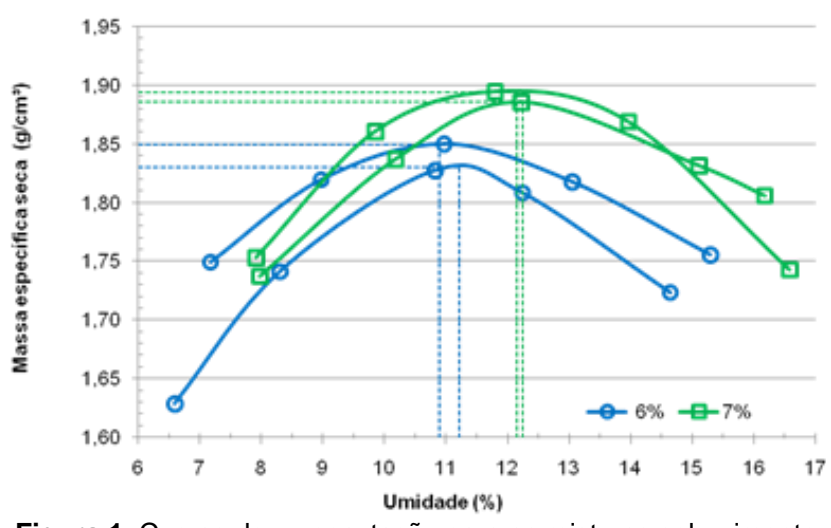

Figura 1. Curvas de compactação para as misturas solo-cimento com 6 e $7 \%$ de cimento

De posse dos dados que originaram as curvas de compactação foram obtidos os valores médios para $\rho_{d \max } \mathrm{e}$ $\omega_{\text {ótima }}$, para cada um dos dois teores de cimento. Tais valores estão apresentados na Tabela 3.

Tabela 3. Resultados obtidos das curvas de compactação com energia Normal de Proctor

\begin{tabular}{|c|c|c|c|c|}
\hline Curva & $\begin{array}{c}\text { Teor de } \\
\text { Cimento }(\%)\end{array}$ & $\begin{array}{c}\text { Cótima } \\
(\%)\end{array}$ & $\begin{array}{c}\rho d \max \\
\left(\mathrm{g} / \mathrm{cm}^{3}\right)\end{array}$ & $\begin{array}{c}\text { Energia de } \\
\text { compactação }\end{array}$ \\
\hline 1 & 6 & 11,2 & 1,83 & Normal \\
\hline 2 & 6 & 10,9 & 1,85 & Normal \\
\hline \multicolumn{2}{|r|}{ Média } & 11,1 & 1,84 & - \\
\hline 3 & 7 & 12,2 & 1,89 & Normal \\
\hline 4 & 7 & 12,3 & 1,89 & Normal \\
\hline \multicolumn{2}{|r|}{ Média } & 12,3 & 1,89 & - \\
\hline
\end{tabular}

1. $\omega_{\text {ótima }}:$ teor de umidade ótima; $\rho_{\text {dmax }}$ : massa específica aparente seca máxima.

Da Tabela 3 têm-se $\omega_{\text {ótima }}$ e $\rho_{\text {dmax }}$ médios de: $11,1 \%$ e $1,84 \mathrm{~g} / \mathrm{cm}^{3}$ para o teor de $6 \%$ e de $12,3 \%$ e $1,89 \mathrm{~g} / \mathrm{cm}^{3}$ para o teor de $7 \%$ de cimento.

Nota-se que a $\rho_{d \max }$ aumentou com a adição de cimento, indicando a diminuição da porosidade da mistura e aumento da cimentação. Isso se deve a quantidade de cimento usado, pois ao adicionar cimento na mistura aumenta-se a quantidade de finos e assim a superfície específica a ser hidratada, necessitando de mais água.

$\mathrm{Na}$ Tabela 4 estão a média dos resultados do teor de umidade, da massa específica aparente seca, do grau de compactação, da absorção de água e da resistência à compressão simples (RSC) das baterias $1,2,9$ e 10 ( $\omega_{\text {ótima }} \mathrm{e}$ energia Normal de Proctor). Na Figura 2 está apresentada à relação entre o intervalo de tempo até a aplicação versus a RCS do solo-cimento.

De acordo com a Tabela 4 alguns valores não atenderam às condições de contorno da pesquisa, em relação ao desvio de $\omega, \rho_{d}$, GC e RCS, fato decorrido do aumento do intervalo de tempo até a aplicação do solo-cimento.

Com o aumento no intervalo de tempo até a aplicação ocorre a diminuição do teor de umidade, por evaporação da água. Consequentemente não é obtida a massa específica aparente seca máxima, por causa do aumento da porosidade, ficando abaixo do valor requerido e, além disso, ocorre o aumento da absorção de água. 
Tabela 4. Média dos resultados das baterias 1, 2, 9 e 10

\begin{tabular}{|c|c|c|c|c|c|c|c|c|c|c|}
\hline & \multicolumn{10}{|c|}{ Intervalo de tempo até a aplicação (min) } \\
\hline & $\mathbf{0}$ & 15 & 30 & 45 & 60 & 90 & 120 & 150 & 180 & 360 \\
\hline \multicolumn{11}{|c|}{ Baterias 1 e $2-6 \%$ de cimento, $\omega_{o t i m a}$ e energia Normal de Proctor } \\
\hline$\omega$ média $(\%)$ & $* 11,3$ & $* 11,1$ & $* 10,8$ & $* 10,7$ & $* 10,4$ & 10,0 & 9,9 & 9,8 & 9,6 & 9,4 \\
\hline$\rho_{d}$ média $\left(\mathrm{g} / \mathrm{cm}^{3}\right)$ & $* 1,84$ & $* 1,84$ & $* 1,84$ & 1,83 & 1,81 & 1,80 & 1,78 & 1,75 & 1,70 & 1,60 \\
\hline GC médio (\%) & $* 100,0$ & $* 100,0$ & $* 100,0$ & 99,5 & 98,4 & 97,8 & 91,8 & 90,2 & 87,6 & 82,5 \\
\hline Absorção média (\%) & 0,6 & 1,0 & 1,5 & 2,4 & 3,2 & 4,2 & 5,0 & 6,1 & 7,2 & 8,9 \\
\hline RCS média $\left(\mathrm{kg} / \mathrm{cm}^{2}\right)$ & $* 21,83$ & 20,57 & 20,45 & 20,14 & 19,13 & 17,40 & 15,87 & 14,62 & 12,91 & 9,13 \\
\hline \multicolumn{11}{|c|}{ 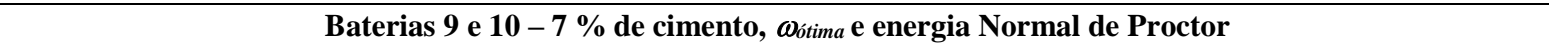 } \\
\hline$\omega$ médio $(\%)$ & $* 12,1$ & $* 11,4$ & $* 11,4$ & $* 11,4$ & $* 11,3$ & 11,2 & 11,1 & 10,6 & 10,3 & 10,0 \\
\hline$\rho_{d}$ média $\left(\mathrm{g} / \mathrm{cm}^{3}\right)$ & $* 1,90$ & $* 1,89$ & 1,88 & 1,85 & 1,81 & 1,78 & 1,74 & 1,74 & 1,73 & 1,62 \\
\hline GC médio (\%) & $* 100,5$ & $* 100,0$ & 99,5 & 97,9 & 95,8 & 94,2 & 92,1 & 92,1 & 91,5 & 85,7 \\
\hline Absorção média (\%) & 0,6 & 1,0 & 1,3 & 2,1 & 2,9 & 3,7 & 4,5 & 5,7 & 7,1 & 8,6 \\
\hline RCS média $\left(\mathrm{kg} / \mathrm{cm}^{2}\right)$ & $* 21,62$ & $* 21,26$ & 20,58 & 19,42 & 16,61 & 12,89 & 12,66 & 8,85 & 8,33 & 7,93 \\
\hline
\end{tabular}

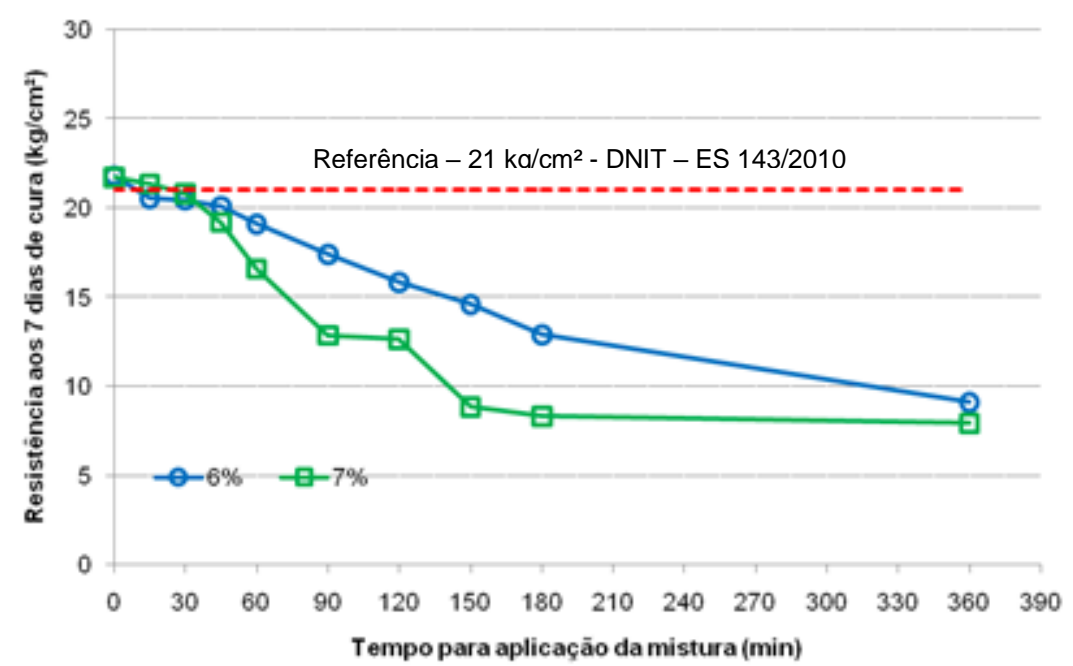

Figura 2. Intervalo de tempo até a aplicação da mistura versus resistência à compressão simples média dos ensaios com teor de cimento de 6 e $7 \%$, umidade ótima e energia Normal do Proctor na compactação

Com isso, para os corpos de prova compactados nos tempos de aplicação nos quais os parâmetros de compactação não foram atendidos, a resistência à compressão simples não atingiu o valor mínimo de $21 \mathrm{~kg} / \mathrm{cm}^{2}$.

Observando a Tabela 4 e a Figura 2 é possível afirmar que, para o solo estudado, quando a mistura de solo-cimento for dosada com umidade igual à ótima e aplicada energia Normal de Proctor, o tempo máximo para a aplicação é de 10 e 21 minutos para os teores de 6 e $7 \%$ de cimento, respectivamente. Esses tempos máximos foram obtidos por interpolação linear dos resultados condicionalmente a resistência mínima à compressão simples de $21 \mathrm{~kg} / \mathrm{cm}^{2}$.

De acordo com a especificação DNIT-ES 143/2010 o tempo entre a homogeneização e a compactação da mistura solo-cimento não deve ser superior a 1 hora quando utilizada usina misturadora e 3 horas quando utilizada mistura na pista.

Mesmo a mistura solo-cimento sendo compactada dentro do intervalo determinado pela especificação DNITES 143/2010 verifica-se o não atendimento da resistência à compressão simples mínima após o tempo de 10 e 21 minutos para os teores de 6 e $7 \%$, respectivamente. Observa-se que após a homogeneização da mistura de solo-cimento em usina as atividades de carga, descarga e espalhamento do material, ultrapassam o tempo de 10 e 21 minutos, não possibilitando a utilização da mistura solo-cimento em campo, com o solo usado neste estudo.

Uma vez que os primeiros ensaios (baterias 1, 2, 9 e 10) apontaram para uma necessidade de modificação nos componentes da dosagem do solo-cimento, foi dado prosseguimento nos ensaios com a realização de quatro baterias $(3,4,5$ e 6$)$ para $6 \%$ e quatro baterias $(11,12,13$ e 14$)$ para $7 \%$ de cimento, com o aumento na dosagem de água para $1 \%$ acima da umidade ótima $\left(\omega_{o ́ t i m a}+1 \%\right)$ e utilizando energia Normal de Proctor.

Após a realização destas baterias de ensaios foram obtidos os resultados médios que estão apresentados na Tabela 5. Na Figura 3 é mostrada a relação entre o intervalo de tempo até a aplicação da mistura versus a RCS.

Novamente para alguns tempos de aplicação da mistura não foram atingidos $\omega, \rho_{d}$, GC e RCS, fato decorrido do aumento do intervalo de tempo até a aplicação do solocimento. 
CANCIAN, M.A.; CANCIAN, V.A.; TEIXEIRA, R.S.; FONTENELE, H.B., COSTA BRANCO, C.J.M.

Tabela 5. Média dos resultados obtidos nas baterias 3, 4, 5, 6, 11, 12, 13 e 14

\begin{tabular}{|c|c|c|c|c|c|c|c|c|c|c|}
\hline & \multicolumn{10}{|c|}{ Intervalo de tempo até a aplicação (min) } \\
\hline & $\mathbf{0}$ & 15 & 30 & 45 & 60 & 90 & 120 & 150 & 180 & 360 \\
\hline \multicolumn{11}{|c|}{ Baterias 3, 4, 5 e $6-6 \%$ de cimento, $\omega_{o t i m a}+1 \%$ e energia Normal de Proctor } \\
\hline$\omega$ média $(\%)$ & $* 12,0$ & $* 11,7$ & $* 11,5$ & $* 11,3$ & $* 11,2$ & $* 10,9$ & $* 10,7$ & $* 10,5$ & $* 10,3$ & 9,6 \\
\hline$\rho_{d} \operatorname{média}\left(\mathrm{g} / \mathrm{cm}^{3}\right)$ & $* 1,84$ & $* 1,84$ & $* 1,84$ & $* 1,84$ & 1,83 & 1,81 & 1,78 & 1,76 & 1,73 & 1,66 \\
\hline GC médio (\%) & $* 100,0$ & $* 100,0$ & $* 100,0$ & $* 100,0$ & 99,5 & 98,4 & 96,7 & 95,7 & 94,0 & 90,2 \\
\hline Absorção média (\%) & 0,5 & 0,9 & 1,2 & 1,9 & 2,8 & 3,5 & 4,4 & 5,6 & 7,0 & 8,5 \\
\hline RCS média $\left(\mathrm{kg} / \mathrm{cm}^{2}\right)$ & $* 21,73$ & $* 21,42$ & $* 21,15$ & 20,47 & 19,55 & 17,88 & 16,2 & 14,52 & 12,48 & 10,57 \\
\hline \multicolumn{11}{|c|}{ Baterias 11, 12, 13 e $14-7 \%$ de cimento, $\omega_{\text {ottima }}+1 \%$ e energia Normal de Proctor } \\
\hline$\omega$ média $(\%)$ & $* 13,1$ & $* 12,9$ & $* 12,7$ & $* 12,5$ & $* 12,3$ & $* 12,1$ & $* 11,9$ & $* 11,7$ & $* 11,5$ & 10,1 \\
\hline$\rho_{d}$ média $\left(\mathrm{g} / \mathrm{cm}^{3}\right)$ & $* 1,90$ & $* 1,89$ & $* 1,89$ & $* 1,89$ & 1,86 & 1,85 & 1,81 & 1,79 & 1,78 & 1,75 \\
\hline GC médio (\%) & $* 100,5$ & $* 100,00$ & $* 100,0$ & $* 100,0$ & 98,4 & 97,9 & 95,8 & 94,7 & 94,2 & 92,6 \\
\hline Absorção média (\%) & 0,3 & 0,7 & 1,1 & 1,9 & 2,7 & 3,2 & 4,1 & 5,4 & 6,8 & 8,2 \\
\hline RCS média $\left(\mathrm{kg} / \mathrm{cm}^{2}\right)$ & $* 26,46$ & $* 25,43$ & $* 21,94$ & $* 21,55$ & 20,23 & 19,77 & 16,55 & 12,48 & 11,95 & 8,83 \\
\hline
\end{tabular}

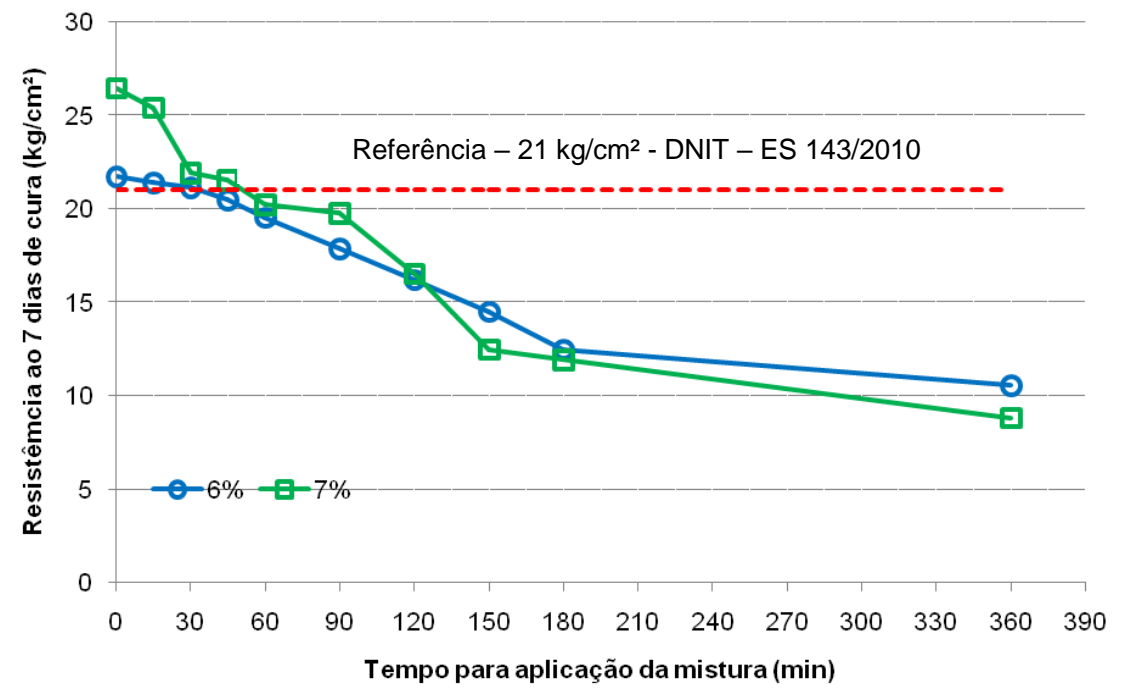

Figura 3. Intervalo de tempo até a aplicação da mistura versus resistência à compressão simples média dos ensaios com teor de cimento de 6 e $7 \%$, umidade ótima $+1 \%$ e energia Normal de Proctor na compactação

Porém, com o aumento em $1 \%$ no teor de umidade ótima, ocorreu aumento da resistência do solo-cimento para todos os intervalos de aplicação, devido ao aumento da hidratação do cimento, gerando um melhor desempenho mecânico das misturas, como mostra a Figura 3.

Mesmo neste caso, ainda para alguns intervalos de tempo até a aplicação não foi atingida a RCS mínima requerida de $21 \mathrm{~kg} / \mathrm{cm}^{2}$.

Desses resultados é possível afirmar que, quando a mistura de solo-cimento for dosada com umidade igual à ótima $+1 \%$ e aplicada energia Normal de Proctor na compactação, o tempo máximo, entre homogeneização e compactação, é de 33 minutos e 51 minutos, respectivamente, para o teor de 6 e $7 \%$ de cimento, com um aumento de 3,3 e 2,4 vezes em relação à dosagem anterior. Esses tempos máximos foram obtidos por interpolação linear, dos resultados da Tabela 5, condicionalmente a resistência mínima à compressão simples de $21 \mathrm{~kg} / \mathrm{cm}^{2}$.

Visto que, os resultados das baterias $1,2,3,4,5,6$, $9,10,11,12,13$ e 14 apontaram para uma necessidade de modificação na dosagem das misturas, para aumentar o intervalo de tempo até a aplicação, foram realizadas mais 2 baterias para cada teor de cimento, baterias 7 e $8(6 \%$ de cimento) e baterias 15 e 16 ( $7 \%$ de cimento).

Estes ensaios objetivaram a verificação do tempo máximo para a aplicação, que poderia ser imposto à mistura de solo-cimento, com a condição de atender à resistência mínima solicitada de $21 \mathrm{~kg} / \mathrm{cm}^{2}$. Para isso, foi necessário manter constante outras duas variáveis do solo-cimento: a umidade e a massa específica aparente seca. Foi mantida a dosagem de água referente $\omega_{\text {otima }}+1 \%$ e para a massa específica aparente seca, buscou garantir o valor obtido nos ensaios das curvas de compactação, aplicando a energia necessária para tal. Na Tabela 6 está a média dos resultados dos ensaios das baterias 7, 8, 15 e $16\left(\omega_{\text {ótima }}+1 \%\right.$ e energia alterada) e na Figura 4 tem-se à relação entre o intervalo de tempo até a aplicação versus a RCS da mistura.

Ao realizar a dosagem para 6 e $7 \%$ de cimento incorporado em massa, mantendo a quantidade de água relativa à $\omega_{\text {ótima }}+1 \%$, e alterando-se a energia de compactação, foi possível verificar que apenas o teor de umidade para o tempo de 360 min não obedeceu ao desvio imposto no trabalho para $7 \%$ de cimento. Este tempo está acima do tempo máximo referenciado pelas normativas vigentes. Mas em todos os outros intervalos de intervalo de tempo até a aplicação, foram atingidos os parâmetros de compactação $\rho_{d} \mathrm{e}$ GC dos corpos de prova, para 6 e $7 \%$ de cimento. Isso promoveu em todos os tempos a diminuição da absorção de água, por causa do decréscimo da porosidade, obtendo os maiores valores de resistência mecânica para os dois teores de cimento utilizados. 
Tabela 6. Média dos resultados obtidos nas baterias 7, 8, 15 e 16

\begin{tabular}{|c|c|c|c|c|c|c|c|c|c|c|}
\hline & \multicolumn{10}{|c|}{ Intervalo de tempo até a aplicação (min) } \\
\hline & $\mathbf{0}$ & 15 & 30 & 45 & 60 & 90 & 120 & 150 & 180 & 360 \\
\hline \multicolumn{11}{|c|}{ Baterias 7 e $8-6 \%$ de cimento, $\omega$ ótimo $+1 \%$ e energia alterada } \\
\hline$\omega$ média $(\%)$ & $* 11,9$ & $* 11,8$ & $* 11,5$ & $* 11,3$ & $* 11,1$ & $* 10,9$ & $* 10,7$ & $* 10,5$ & $* 10,4$ & $* 10,1$ \\
\hline$\rho_{d}$ média $\left(\mathrm{g} / \mathrm{cm}^{3}\right)$ & $* 1,84$ & $* 1,84$ & $* 1,84$ & $* 1,84$ & $* 1,84$ & $* 1,84$ & $* 1,84$ & $* 1,84$ & $* 1,84$ & $* 1,84$ \\
\hline GC médio (\%) & $* 100,0$ & $* 100,0$ & $* 100,0$ & $* 100,0$ & $* 100,0$ & $* 100,0$ & $* 100,0$ & $* 100,0$ & $* 100,0$ & $* 100,0$ \\
\hline Número de golpes & 25 & 28 & 31 & 34 & 37 & 40 & 43 & 46 & 49 & 52 \\
\hline $\begin{array}{l}\text { Energia de compactação } \\
\left(\text { kgf.cm/ } / \mathrm{cm}^{3}\right)\end{array}$ & 5,72 & 6,41 & 7,09 & 7,78 & 8,46 & 9,15 & 9,84 & 10,52 & 11,21 & 11,90 \\
\hline Absorção média (\%) & 0,3 & 0,4 & 0,4 & 0,5 & 0,5 & 0,6 & 0,6 & 0,6 & 0,6 & 0,7 \\
\hline RCS média $\left(\mathrm{kg} / \mathrm{cm}^{2}\right)$ & $* 24,05$ & $* 23,10$ & $* 22,67$ & $* 21,76$ & $* 21,46$ & 20,88 & 20,76 & 19,57 & 19,37 & 14,05 \\
\hline \multicolumn{11}{|c|}{ Baterias 15 e $16-7 \%$, wótimo + $1 \%$ e energia alterada } \\
\hline$\omega$ média $(\%)$ & $* 13,1$ & $* 12,8$ & $* 12,7$ & $* 12,5$ & $* 12,4$ & $* 12,2$ & $* 11,8$ & $* 11,7$ & $* 11,5$ & 10,1 \\
\hline$\rho_{d}$ média $\left(\mathrm{g} / \mathrm{cm}^{3}\right)$ & $* 1,90$ & $* 1,89$ & $* 1,89$ & $* 1,90$ & $* 1,90$ & $* 1,89$ & $* 1,90$ & $* 1,89$ & $* 1,89$ & $* 1,89$ \\
\hline GC médio $(\%)$ & $* 100,0$ & $* 100,0$ & $* 100,0$ & $* 100,0$ & $* 100,0$ & $* 100,0$ & $* 100,0$ & $* 100,0$ & $* 100,0$ & $* 100,0$ \\
\hline Número de golpes & 25 & 28 & 31 & 34 & 37 & 40 & 43 & 46 & 49 & 52 \\
\hline $\begin{array}{l}\text { Energia de compactação } \\
\left(\mathrm{kgf} . \mathrm{cm} / \mathrm{cm}^{3}\right)\end{array}$ & 5,72 & 6,41 & 7,09 & 7,78 & 8,46 & 9,15 & 9,84 & 10,52 & 11,21 & 11,90 \\
\hline Absorção média (\%) & 0,3 & 0,4 & 0,4 & 0,5 & 0,5 & 0,5 & 0,6 & 0,6 & 0,6 & 0,6 \\
\hline RCS média $\left(\mathrm{kg} / \mathrm{cm}^{2}\right)$ & $* 26,02$ & $* 25,36$ & $* 24,43$ & $* 23,70$ & $* 23,3$ & $* 22,55$ & 20,74 & 20,41 & 19,88 & 14,56 \\
\hline
\end{tabular}

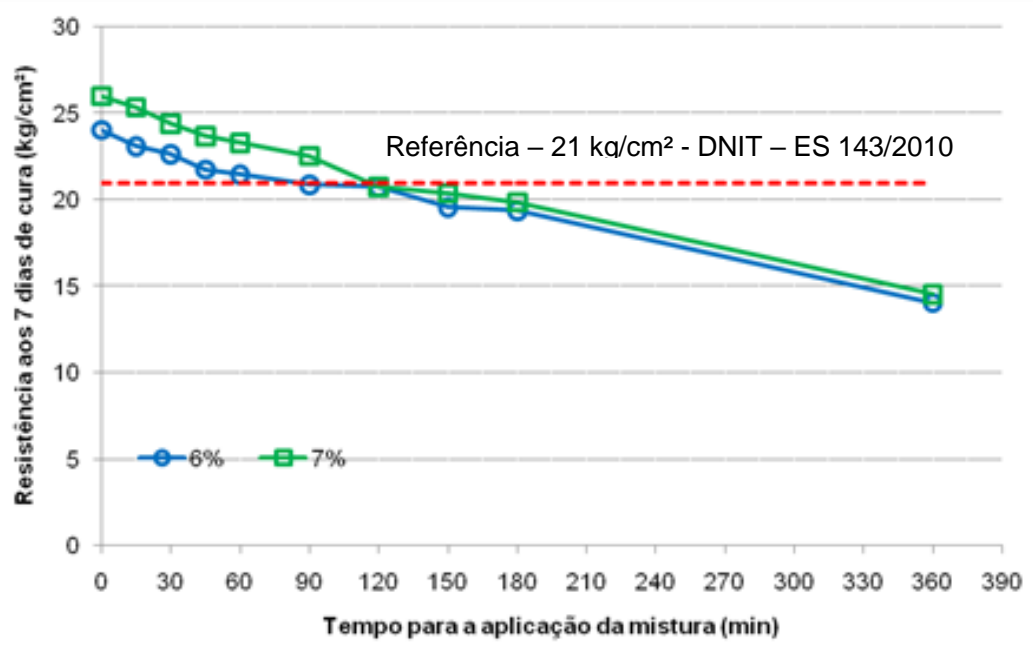

Figura 4. Intervalo de tempo até a aplicação da mistura versus resistência à compressão simples média dos ensaios com teor de cimento de 6 e $7 \%$, umidade ótima + $1 \%$ e energia alterada na compactação

Dos resultados mostrados na Tabela 6 e as tendências da Figura 4 é possível afirmar que, quando a mistura de solo-cimento for dosada com umidade igual à ótima mais $1 \%$ e aplicada energia alterada na compactação, o tempo máximo de aplicação é de 1 hora e 24 minutos ( 84 min) para o teor de $6 \%$ de cimento e 1 hora e 56 minutos (116 min) para o teor de $7 \%$ de cimento.

Esses tempos foram obtidos por interpolação linear dos resultados da Tabela 6 , relativos à resistência mínima à compressão simples de $21 \mathrm{~kg} / \mathrm{cm}^{2}$. Esta dosagem aumentou o tempo máximo de aplicação do solo-cimento em 2,5 para o teor de $6 \%$ e em 2,3 para $7 \%$ de cimento incorporado, em relação à dosagem anterior, apenas com a modificação da energia.

Para aumentar o intervalo de tempo até a aplicação foi necessário aumentar a energia de compactação. Esse fato confirma que a resistência à compressão simples, do solo-cimento é melhor para a máxima massa específica aparente seca na compactação, pois nessa condição o solo-cimento apresenta menor volume de vazios, portanto, maior número de contatos entre os grãos do solo e o cimento, aumentando a resistência mecânica da mistura solo-cimento.
Para os corpos de prova compactados, na umidade ótima e massa específica aparente seca, nos primeiros tempos para a aplicação as resistências foram maiores quando comparadas com as resistências para tempos maiores, mesmo sendo atingidos o teor de umidade e a massa específica aparente.

O aumento do tempo para aplicação, em todas as dosagens para os dois teores de cimento, fez com que a mistura solo-cimento diminuísse sua resistência à compressão simples. Nos primeiros tempos, a aplicação de energia é realizada quando o solo-cimento está em seu estado solto e seu endurecimento ocorre no estado compacto. Além disso, nos primeiros intervalos de homogeneização o teor de umidade é o ótimo, ou está próximo a este no momento da compactação, e nessa situação a hidratação do cimento ocorre no estado compacto, gerando maior contato entre o solo e o cimento, resultando em resistências maiores.

Em relação aos intervalos maiores, ocorre o inverso, como já aconteceram às reações para a hidratação do cimento, a compactação ocorre no seu estado endurecido, o que diminui os pontos de contato entre os grãos de solo e cimento, elevando a porosidade e ocasionando perda de umidade. 


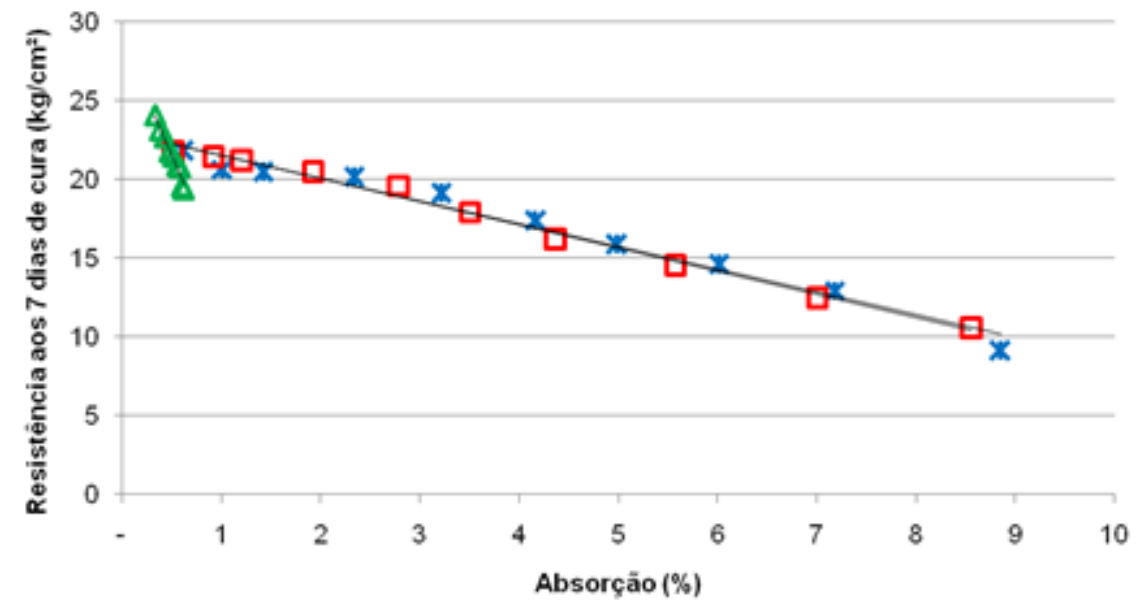

XWótima e Energia Normal $\quad$ aWótima $+1 \%$ e Energia Normal $\Delta$ Wötima $+1 \%$ e Energia Alterada

Figura 5. Absorção de água média após imersão por 4 horas versus resistência à compressão simples média - Teor de cimento de 6 \%

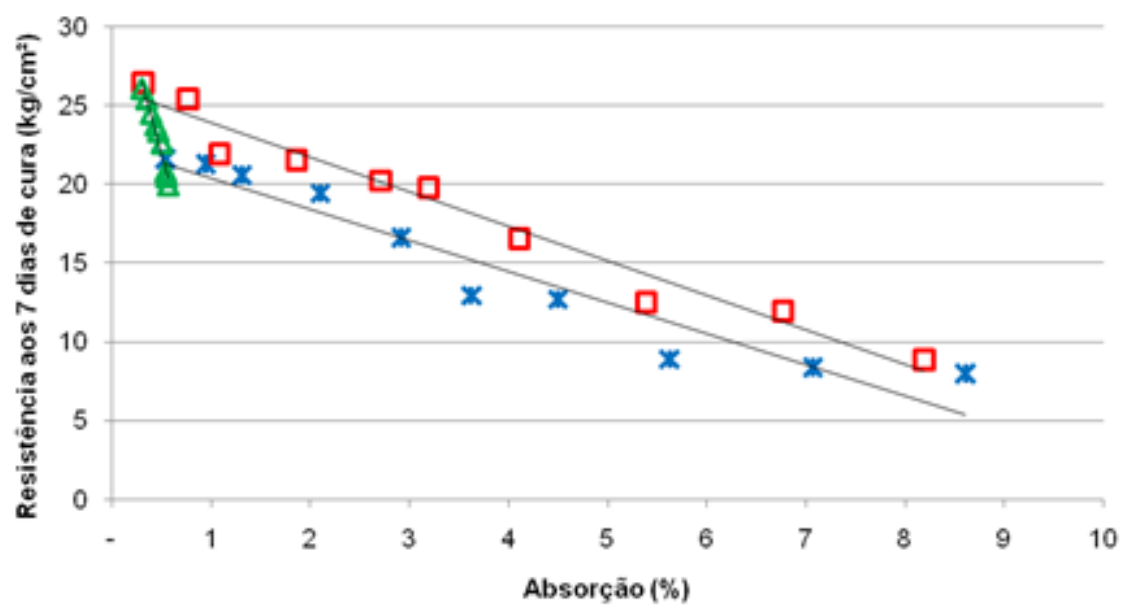

xWótima e Energia Normal $\quad$ WWotima $+1 \%$ e Energia Normal $\Delta$ Wótima $+1 \%$ e Energia Alterada

Figura 6. Absorção de água média após imersão por 4 horas versus resistência à compressão simples média - Teor de cimento de 7 \%

Por isso, é necessária maior energia na compactação para alcançar a $\rho_{\text {dmax }}$ determinada na curva de compactação. Como consequência o solo-cimento apresenta um desempenho mecânico inferior aos primeiros tempos.

Foram verificadas melhorias de até $55 \%$ na resistência à compressão simples para a mistura com teor de $6 \%$ de cimento e de $63 \%$ para a mistura com $7 \%$ de cimento, quando foi alterada a energia de compactação, de modo que a moldagem fosse realizada com massa específica aparente seca máxima e menor porosidade, com isso mais pontos de cimentação.

Dos dados das Tabelas 4, 5 e 6 foram feitas as Figuras 5 e 6, que apresentam a relação entre a absorção de água média versus RCS média para 6 e $7 \%$ de cimento.

A partir das Figuras 5 e 6, foi possível avaliara influência da porosidade na resistência à compressão simples das misturas solo-cimento. A resistência à compressão simples do solo-cimento varia linearmente com a absorção de água, mostrando que, quanto menor a absorção de água menor porosidade e menor índice de vazios da mistura, com isso mais pontos de contato entre os grãos de solo e cimento, otimizando a cimentação e melhorando o desempenho mecânico do solo-cimento.
Observa-se então, que a massa específica aparente seca da mistura solo-cimento compactada deve ter um controle rigoroso nas obras de pavimentação, que se utilizam desta solução de engenharia. A diminuição da porosidade acarreta no aumento do número de contatos entre o cimento e as partículas de solo, ocasionando maior hidratação do cimento, favorecendo a cimentação da mistura.

Vale ressaltar que não se objetivou nesta parte da pesquisa encontrar uma metodologia racional para dosagem de solo-cimento, e sim, verificar qual a interferência da absorção no solo-cimento.

\section{CONCLUSÕES}

Dos resultados e análises realizadas, foi confirmado em relação ao intervalo de tempo até a aplicação da mistura solo-cimento, que o mesmo influencia diretamente na resistência à compressão simples. Quanto se aumenta o intervalo de tempo até a aplicação, ocorre diminuição da resistência à compressão simples. Os tempos para as dosagens de $6 \mathrm{e}$ $7 \%$ de cimento foram limitados, respectivamente, em: $10 \mathrm{e}$ 21 min para dosagem com teor de umidade ótima e energia Normal de Proctor; 33 e 51 min para a dosagem com teor de umidade ótima $+1 \%$ e energia Normal de Proctor e $1 \mathrm{~h} 24$ 
$\min (84 \mathrm{~min})$ e $1 \mathrm{~h} 56 \mathrm{~min}(116 \mathrm{~min})$ para a dosagem do teor de umidade ótimo $+1 \%$ e energia alterada.

Com relação à variação do teor de umidade da mistura solo-cimento após a compactação, mantida a massa específica aparente seca máxima, foram verificadas significativas alterações na resistência à compressão simples. Ao diminuir o teor de umidade da mistura a ser compactada ocorre menor hidratação do cimento, com consequente diminuição da resistência a compressão simples da mistura após sua compactação.

Quando realizada a compactação da mistura com teor de umidade ótimo $+1 \%$, elevou-se a resistência e o intervalo de tempo até a aplicação da mistura solo-cimento para os dois teores de cimento 6 e $7 \%$.

Ao analisar a relação da porosidade com a absorção de água após imersão dos corpos de prova das misturas compactadas (por 4 horas) constatou-se que para as misturas menos porosas redução da absorção de água, provocando considerável ganho na resistência à compressão simples.

A energia usada na compactação da mistura mostrouse como importante fator para obtenção de maior intervalo de tempo até a aplicação do solo-cimento. Nos corpos de prova onde foi usada a energia de compactação alterada, para atingir a massa específica aparente seca máxima dos corpos de prova, verificou-se aumento considerável na resistência à compressão simples das misturas.

Foi constatada que a RCS da mistura solo-cimento é diretamente proporcional ao aumento do teor de cimento e inversamente proporcional ao intervalo de tempo até a aplicação. Por isso, quando for preciso em campo um tempo maior para a aplicação da mistura solo-cimento, será necessário alterar o teor de cimento e ou o teor de umidade e ou a energia de compactação para atingir a RCS mínima exigida na especificação DNIT-ES 143/2010.

Os resultados e análises deste trabalho podem nortear a elaboração ou alteração de normas no que diz respeito à limitação do tempo máximo para a aplicação de mistura solo-cimento compactada para emprego em pavimento. Existe ainda a necessidade de avaliar um maior banco de amostras, com diferentes características físicas, para aferir e refinar os resultados obtidos no presente trabalho.

\section{REFERÊNCIAS}

ABCP (2013) Estradas de concreto: este é o caminho para o futuro. Associação Brasileira de Cimento Portland. Brasil.

ABNT (1984) NBR 6508 - Grãos de solo que passam na peneira de 4,8 mm - Determinação da massa específica aparente: Método de ensaio. Associação Brasileira de Normas Técnicas, Rio de Janeiro.

ABNT (1986) NBR 7182 - Solo - Ensaio de Compactação. Associação Brasileira de Normas Técnicas, Rio de Janeiro.

ABNT (1988) NBR 10838 - Solo - Determinação da massa específica aparente amostras indeformadas, com emprego de balança hidrostática: Método de ensaio. Associação Brasileira de Normas Técnicas, Rio de Janeiro.

ABNT (1988) NBR 7181 - Solos -Análise granulometrica: Método de ensaio. Associação Brasileira de Normas Técnicas, Rio de Janeiro.
CONSOLI, N. C.; FOPPA, D.; FESTUGATO, L.; HEINECK, K. S. (2007) Key parameters for strength control of artificially cemented soils. Journal of Geotechnical and Geoenvironmental Engineering. New York: ASCE, v.133, n.2, p. 197-205.

\section{DOI: 10.1061/(ASCE) 1090-241(2007)133:2(197)}

DNER (1994) ME 122 - Solos - Determinação do limite de liquidez. Departamento Nacional de Estradas de Rodagem. Diretoria de Desenvolvimento Tecnológico - IPR. Rio de Janeiro.

DNER (1994) ME 201 - Solo-cimento - compressão axial de corpos de prova cilíndrico. Departamento Nacional de Estradas de Rodagem. Diretoria de Desenvolvimento Tecnológico - IPR. Rio de Janeiro.

DNER (1994) ME 202-Solo-cimento - moldagem e cura de corpos de prova cilíndricos. Departamento Nacional de Estradas de Rodagem. Diretoria de Desenvolvimento Tecnológico - IPR. Rio de Janeiro.

DNER (1994) ME 213 - Solos - determinação do teor de umidade: método de ensaio. Departamento Nacional de Estradas de Rodagem. Diretoria de Desenvolvimento Tecnológico - IPR. Rio de Janeiro.

DNER (1994) ME 216 - Solo-cimento - determinação da relação entre o teor de umidade e a massa específica aparente. Departamento nacional de Estradas de Rodagem. Diretoria de Desenvolvimento Tecnológico - IPR. Rio de Janeiro.

DNER (1994) ME 256 - Solos - compactados por equipamento miniatura - perda de massa por imersão. Departamento Nacional de Estradas de Rodagem. Diretoria de Desenvolvimento Tecnológico - IPR. Rio de Janeiro.

DNER (1994) ME 258 - Solos - compactados por equipamento miniatura Mini - MCV. Departamento Nacional de Estradas de Rodagem. Diretoria de Desenvolvimento Tecnológico - IPR. Rio de Janeiro.

DNER (1994) ME 49 - Solos - Determinação do Índice de Suporte Califórnia. Departamento Nacional de Estradas de Rodagem. Diretoria de Desenvolvimento Tecnológico - IPR. Rio de Janeiro.

DNER (1994) ME 80 - Solo- Análise granulométrica por peneiramento. Departamento Nacional de Estradas de Rodagem. Diretoria de Desenvolvimento Tecnológico - IPR. Rio de Janeiro.

DNER (1994) ME 82 - Solos - Determinação do limite de plasticidade. Departamento Nacional de Estradas de Rodagem. Diretoria de Desenvolvimento Tecnológico - IPR. Rio de Janeiro.

DNIT (2006) - Departamento Nacional de Infraestrutura de Transportes. Diretoria de Planejamento e Pesquisa.Coordenação Geral de Estudos e Pesquisa. Instituto de Pesquisas Rodoviárias. Manual de Pavimentação. 3. ed. p. 56. Rio de Janeiro.

DNIT (2010) ES 143 - Pavimentação - Base de solo-cimento Especificação de serviço. Departamento Nacional de Infraestrutura de Transportes. Diretoria de Planejamento e Coordenação Geral de Estudos e Pesquisa. Instituto de Pesquisas Rodoviárias. Rio de Janeiro.

FELT, E. J. Factors influencing phisical proprieties of soilcement mixtures. Highway Research Bulletin. $\mathrm{N}^{\circ} 108$, p. $138-$ 162. 1955. The national Academies of SCIENCES ENGINEERING - MEDICINE. 
FREIRE, W. Avaliação física, mecânica e térmica de misturas de solo-cimento adicionadas de cinza de casca de arroz sem atividade pozolânica. Universidade Estadual de Campinas. UNICAMP, São Paulo. 2008.

LOPES, W. G. R. Solo-cimento reforçado com bambu características físico mecânicas. Tese de doutorado. Universidade Estadual de Campinas. Faculdade de Engenharia Agrícola. Campinas, SP, Brasil. 2002.

NEVILLE, A. M. Propriedades do concreto. Pini. São Paulo, SP, Brasil. 1997.

OLIVEIRA, R. F. V. Análise de dois solos modificados com cimento para dimensionamento de pavimentos. Dissertação de mestrado em Engenharia Civil. Universidade Estadual de Ouro Preto. 2011.

PARENTE, E. B. Avaliação do comportamento mecânico das misturas de solo-cimento e fosfogesso e cimento para uso na construção rodoviária. Dissertação de mestrado. Escola de Engenharia de São Carlos. São Carlos, SP, Brasil. 2002.

VITALI, O. P. M. Efeito da composição de misturas de solocimento nos parâmetros de rigidez e de resistência. 2008. Dissertação submetida como requisitos do grau de mestre em engenharia civil - especialização em geotecnia; Faculdade de engenharia- Universidade do Porto. Julho.

WEST, G. (2015) A laboratory Investigation into the effect of elapsed time after mixing on the compaction and strength of soilcement. Géotechnique. v.9, n. 1, p. 22 - 28. DOI:

10.1680/geot.1959.9.1.22 